\title{
IMAGES OF INHABITING AT CAMPO SQUARE IN SIENA: THE INTEGRATION OF BACHELARD'S TOPOANALYSIS IN THE INTERPRETATION OF ARCHITECTURAL AND URBAN SPACES
}

\author{
Susan NOORMOHAMMADI* \\ Independent researcher, Konzeller Str. 15, 85635 Höhenkirchen-Siegertsbrunn, Germany
}

Received 09 June 2016; accepted 10 March 2017

\begin{abstract}
This paper focuses on the perceptual-psychological experience of place in Campo Square, in the Italian city of Siena. Viewed from this perspective, it contributes to Gaston Bachelard's topoanalysis and aims to address a phenomenological analysis of the real, and inhabited images embedded in Campo Square. Bachelard focuses on topoanalysis, which is mainly based on the association of all our senses, most importantly the visual, aural, and tactile, with our lived experiences. The main objectives of this paper are to discover, examine, and interpret the real images that are influential in the creation of strong sense of place attachment in Campo Square. Based on qualitative research, including a textual analysis of Gaston Bachelard's phenomenological imagination, the memorable character of Campo Square will be analyzed. The analysis will then be compared to that of another square, Haidplatz, in Regensburg, Germany. This comparison will reveal links between images of inhabiting (simplicity and protection) and images of our sensory realm in Campo Square and Haidplatz Square. Consequently the findings across the two squares lead the paper to suggest possibilities and solutions in order to propose a framework for the integration of topoanalysis in the interpretation of architecturalurban space.
\end{abstract}

Keywords: Campo Square, Siena, Gaston Bachelard, interpretation, attachment to place, real image, Haidplatz, Regensburg.

\section{Introduction}

The city of Siena, located in the Tuscany region of Italy, is considered to be a significant historical urban example for the purposes of this paper. It is similar to other medieval examples -Bologna, Florence, San Gimignano, and Verona in Italy; Ghent and Bruges in Belgium; Paris in France; Prague in the Czech Republic; Regensburg and Köln in Germany; and York in England - in that it possesses lived, inhabited, and real spaces which are both inspiring and wonderful (Benevolo 1983: 336).

Several crucial factors are involved in the creation of special character in the city center of Siena, particularly, Campo Square. The hypothesis of this paper is that the topoanalysis of Gaston Bachelard can contribute a strong basis for an interpretation of architectural and urban environments. The distinctive communal-gathering character of Campo Square allows people to make strong connections between the place and their personal lives, as well as to memories and the imagination. What gives Campo
Square its distinctive, strong, wonderful, and lovely qualities? By what means can we analyze its memorable character? What are the lived and inhabited images embedded in this square? How do the real/lived and inhabited images of Campo Square come to be imagined, remembered, perceived, and interpreted? How can the strong attachment to Campo Square in relation to its associative meanings be analyzed? In posing such questions, this paper clarifies Bachelard's contribution in an example of urban-architectural interpretation.

The discussion that follows is divided into two main parts. First, the association of memory and imagination in Bachelard's phenomenology is argued. In addition, the distinctive communal-gathering and memorable character of Campo Square and interrelations between the social and the built environment in this place are discussed. A comparison with Haidplatz in Regensburg, Germany, another medieval urban square, is made in order to achieve a more comprehensible analysis. Based

*Corresponding author. E-mail: suzinoor@gmail.com 
on Bachelard's topoanalysis, the second part of the paper considers his contribution to urban interpretation while emphasizing the reciprocal relation between the sensory realm and inhabited images in Campo Square and Haidplatz.

This paper may be most generally characterized as qualitative research, including a textual analysis of Gaston Bachelard's phenomenological imagination and theories relating to the meaning of place. As such, it is strengthened by supporting images from Campo Square and Haidplatz including the main attractions, City Hall and Siena Cathedral, and the principal narrow streets that run into the squares. Furthermore, the main architectural and urban elements of the two squares will be examined, such as buildings, landmarks, and a fountain; consequently, other physical factors will be looked at as well, such as geometry, size, and proportion of the square, materials of the square and buildings, colors, the contrast of light and shadow, and interrelations between people and place. This paper will conclude that the contribution of Bachelard's phenomenology of imagination to the interpretation of architectural-urban environments is possible through four interrelated approaches: an analysis based on the interrelations between sociocultural norms and built forms; an analysis of our sensory realm in confrontation with the built environment; an analysis of images of inhabiting; and an analysis of the reciprocity between our sensory realm and images of inhabiting. In addition, this paper will try to show how the analysis of the connections and contrasts between public, private and semipublic spaces are significant in this approach.

\section{The association of memory and imagination in Bachelard's phenomenology}

Phenomenology, as Neil Leach summarizes, offers an indepth model for understanding human experience: "To engage with architecture, involves an openness not only to the realm of the sensory, but also to the potential revelation of some truth" (Leach 1997: 83). Max van Manen, who defines phenomenology as a meaning-giving method of enquiry, considers it to be hermeneutic or descriptiveinterpretive, and believes that it is a method of reflection on the basic structures of the lived experience of human existence (van Manen 2014: 26).

According to Otero-Pailos, "The intersubjectivity of experience was a fundamental concept in phenomenology, discussed at length by most phenomenologists from Husserl to Heidegger and Bachelard to MerleauPonty" (Otero-Pailos 2010: 138). In this regard, Gaston Bachelard's contribution to the analysis of architectural and urban places is significant, as he considers imagination and memory to be engaged in our deep experiences with the spaces that surround us. His phenomenological analyses are worthwhile in that he analyzes the human need to have "real images" in relationship to place in order to enhance the person-place relationship, and, consequently, to promote the meaning in space. As Edward Casey regarding the essays of Heidegger on Dwelling and Bachelard's notion on inhabitation concludes, "Bachelard's The Poetics of Space has much more to say about the specificities of human dwelling - about its 'countless diversified nuances"' (Casey 1998: 292). Bachelard sensitizes architects and urban planners to the phenomenological interpretation of certain places. He brings valuable examples to the table in order to increase inhabitants' imagination in confronting a space (NoorMohammadi 2015: 81).

Gaston Bachelard (1884-1962), the French phenomenologist, is best known for attempting to focus on the intimate spaces of "human dwellings" and also on the "ideal home". He has contributed greatly to the phenomenological analysis of the "oneiric house" and "inhabited space". In his famous book The Poetics of Space $^{1}$ he attempts to anchor the deep experiences of human beings and stresses two major elements as well as imagination and memory that are significant in the creation of real images. Bachelard's research is devoted to the domain of intimacy, "to the domain in which psychic weight is dominant" (Bachelard 1994: 12). He mentions that "We must return to the field of the primitive images that had perhaps been centers of fixation for recollections left in our memories" (ibid.: 30). In considering the strong solidarity between memory and imagination ${ }^{2}$, Bachelard concentrates on the function of these two connected and interrelated terms in the creation of the real image. By describing the nature of real images as well as simple images as "felicitous space" or "eulogized space" (ibid.: xxxi), Bachelard seeks the spaces that we love and believes that real images are engravings, "for it is the imagination that engraves them on our memories. They deepen the recollections we have experienced, which they replace, thus becoming imagined recollections" (ibid.: 32). He stresses the association of all the major senses - visual, aural, tactile, and olfactory - in referring to the imagination of inhabited space. By reference to memories of the past as well as of the childhood home, Bachelard reminds us of the memories that are intertwined with our senses. At a deeper and higher level, he wants us to go beyond the sensory realm in order to reach to images of the

\footnotetext{
1 First French publication: La Poétique de l'Espace (1958).

2 Vesely (2004) states "like language, imagination can transform the material into a pictorial image eventually into the iconicity of abstract concepts. How the imagination can communicate between such different levels of reality and different areas of culture as architecture, sculpture, painting, language, music, and dance is still little understood" (Vesely 2004: 90).
} 
function of inhabiting (Bachelard 1994: 98). ${ }^{3}$ As he explains, the ideal image must lead us through all our senses and draw us beyond the sense which is most clearly committed (Bachelard 1971: 83).

Place attachment is a positive factor that can contribute to sustaining place identity thus promote psychological well-being, fulfillment and happiness to the urban inhabitants (Ujang, Zakariya 2015: 715). The significance of place and its connections to human experiences is widely discussed and analyzed in the recent researches. Seamon (1996) considers the importance of place "as a powerful conceptual structure as well as an integral part of everyday human life" (Seamon 1996: 7). Relph states "the essence of place lies in the largely unselfconscious intentionality that defines places as profound centers of human existence" (Relph 1976: 43). In the following part of the paper the attachment to Campo Square and Haidplatz with the focus on the memorable character of the squares will be analyzed.

\section{Memorable character of Campo Square}

As Nevola states, "Siena, one of the major artistic centers of medieval and Renaissance Italy, is renowned for its striking architecture and its beauty as a city" (Nevola 2007). Campo Square, in the small Tuscan city of Siena, displays certain, distinctive and memorable characteristics that offer considerable interpretative potential for the purposes of this study. The square is considered to be an historic public place on the scale of an urban plaza. The historic and ritual background of Siena has created a strong sense of attachment in this place. The occurrence of Palio, an historic and

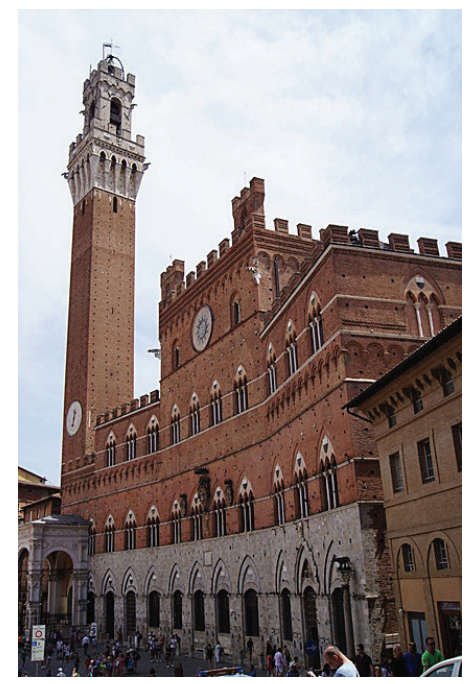

\footnotetext{
3 In Bachelard's thought, "one's experience of reality was ruled by one's imagination, which he described as the 'pre-reflexive attitudes that govern the very process of reflection"' (OteroPailos 2010: 105). Based on Bachelard's theory, by experiencing an object as well as a historic building, one can never experience it truly objectively (Vesely 2004: 60).
}

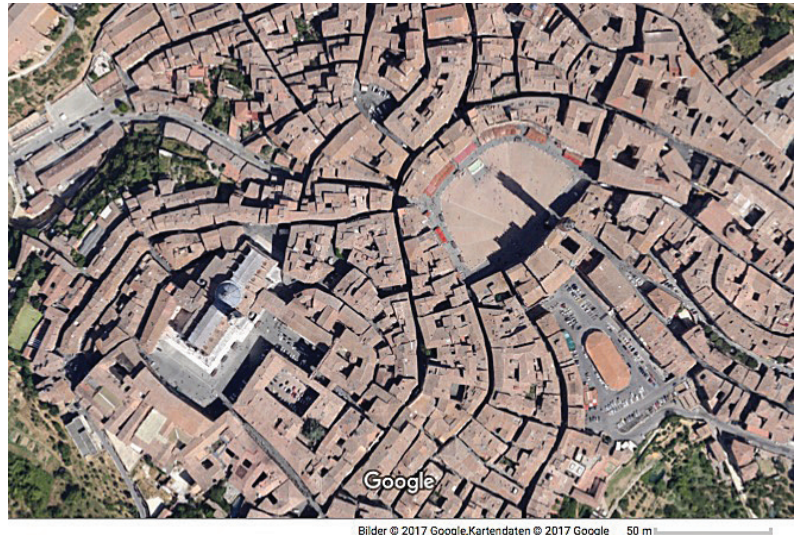

Fig. 1. An overview of the city center of Siena; the shellshaped Campo Square is located in the middle of the image (C) 2017 Google, Maps data (c) 2017 Geobasis-DE/BKG). "Not only the piazza contrast with the surrounding density of the urban fabric, but also the configuration of the streets also reinforces the shape of the square itself" (Trancik 1986: 63).

well-known horse race in Siena which takes place twice in summertime in Campo Square, strengthens the memorable character of the square (Zimmermanns 2011: 288). The city itself is located in the middle of a vast, hilly landscape, and walking its streets provides various different and spectacular views, to which accompanying memories are evoked. In his book Hill Towns of Central Italy, Rick Steves states: "Siena seems to be every Italy connoisseur's favorite town". Steves describes his strong feeling on encountering Campo Square: "Courtyards sport flowerdecked wells, alleys dead-end at rooftop views and sky is a rich blue dome" (Steves 2013: 90). In addition, McGuffin

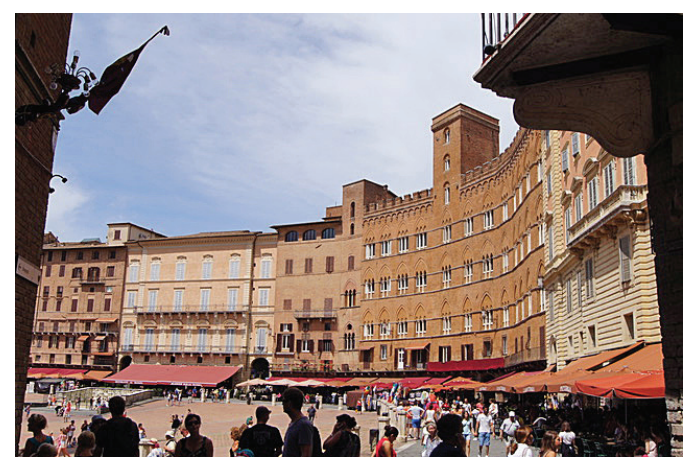

Fig. 2. Campo Square, Left: The campanile of Palazzo Pubblico functions as a strong vertical visual point. Right: view to the northwest. Photo courtesy of the author. 
describes it thus: "It is paved with red brick and is surrounded by cafes, vendors, and local businesses. Viewed from the air it reminds me of a half completed sunset" (McGuffin 2002).

It would be a considerable task to analyze the influential factors in the creation of sense of attachment in Campo Square as well as attraction, wonder, and authenticity. The symmetrical shell-shaped square with an area of about 6,500 square meters is surrounded by harmonious buildings which mostly belong to the thirteen century (Fig. 1). "The piazza del Campo is dominated by the presence of the government palace - the Palazzo Pubblico - and the civic tower of the Torre del Mangia which form the natural back-drop to the amphitheatrelike slope of paved space" (Nevola 2007: 19-20). In addition, the square houses palaces the Palazzo Chigi al Casato and the Palazzo Piccolomini on its southern side, and the Loggia della Mercanzia and Palazzo Sansedoni on its northern side (ibid.: vi).

Trancik describes Campo Square as one of the most effective urban spaces in existence, which offers a number of important lessons to the urban designer. According to him, "Much of its strength as a space stems from the contrast between the dense mass of surrounding buildings and the open piazza.

The campanile of Palazzo Pubblico serves as a vertical focal point. As early as 1262 a city ordinance governing the height and facades of the buildings facing the square [was] effected in recognition of the role a consistent wall plays in defining the character of urban space" (Trancik 1986: 62) (Fig. 2).

Campo Square is considered to be Siena's main public space. As Nevola says, this square has been described as the "civic centerpiece" and its location made the piazza a natural market space: "it is the architectural space, social activity and allegorical figures that interact together to form a compound image of the piazza del Campo itself" (Nevola 2007: 18). Armed with an overview of the significance of Campo Square, we can now turn to the task of considering and discussing a phenomenological analysis of its memorable character.

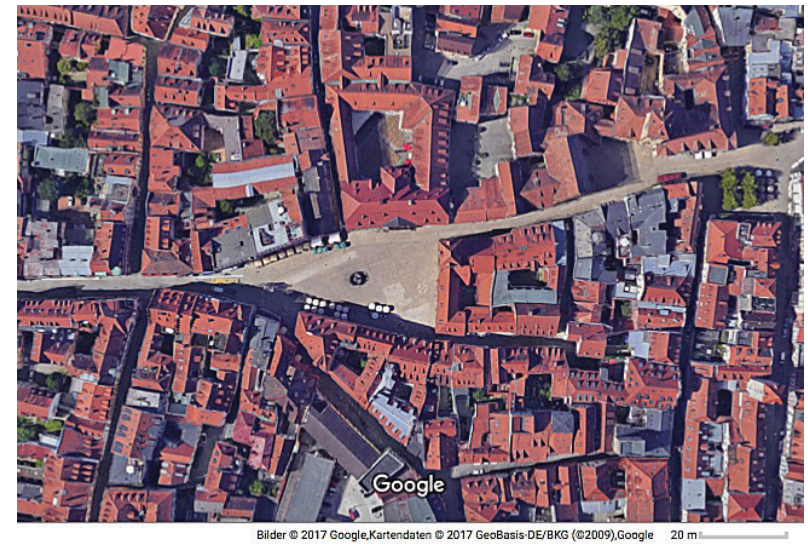

Fig. 3. Part of the map of old town Regensburg. The triangular- shaped Haidplatz is in the middle of the image. Most of the surrounding buildings of Haidplatz dates back to the medieval period (C 2017 Google, Maps data (C) 2017 Geobasis-DE/BKG).

\section{Bachelard's topoanalysis in relation to Campo Square and Haidplatz: the tacit reciprocity between the sensory realm and the function of inhabiting}

In The Poetics of Space, Gaston Bachelard presents his doctrine as a topoanalysis and defines it as "The systematic psychological study of the sites of our intimates lives" (Bachelard 1994: 8). Topoanalysis is mainly based on the association of all our senses, most importantly, the visual, aural, and tactile contacts with our daily experiences in a space. As Casey describes, topoanalysis presupposes the psyche as the seat of all significant images and seeks the detailed description of particular images (Casey 1998: 290). In order to reveal the relationship between images of inhabiting and images of our sensory realm in Campo Square, different emotional-psychological aspects of space will be experienced and interpreted both inside and beyond Campo Square. This task leads to an analysis of the relationship between human imagination and the way in
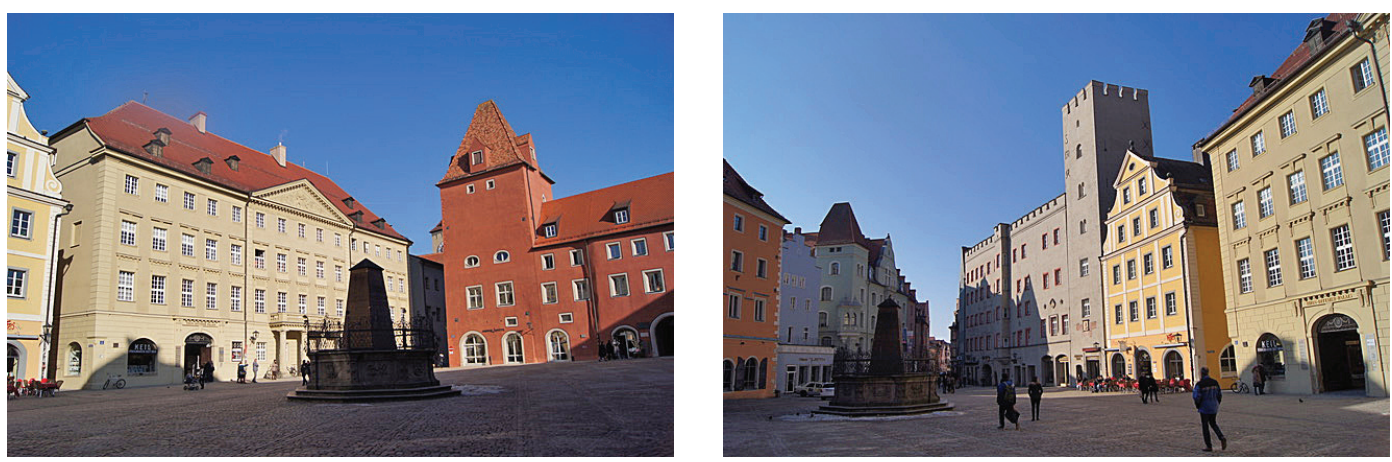

Fig. 4. Left: Haidplatz, view to the east. The justitiabrunnen (fountain) is in the middle. Right: view of Haidplatz to the west. The grey Golden Cross building is in the middle. Photo courtesy of the author. 
which images are implied and engraved on our memories. In order to accomplish this goal and to improve knowledge of the "sense of place", comparison with another urban square is made, to achieve a more comprehensible analysis.

Haidplatz is another example of a medieval urban square. Its selection for the purposes of this paper is made for several specific reasons. Both Campo Square and Haidplatz reflect social and ceremonial functions and are similar in terms of their historical backgrounds (Fig. 3). Despite topographical and geographical differences, the similar historical epoque to which the two squares belong legitimizes the idea of concentrating more on the qualitative aspects of the two places and emphasizing their intimate images.

Regensburg is located in the state of Bavaria in southeast Germany, and the reflections of late antiquity and the Middle Ages in the town point to its high status historically (Moosburger, Morsbach 2009: 20). Haidplatz was the center of a former Roman city; nowadays, with its fountain, cafes and leisure area, it is a popular meeting place for inhabitants and tourists alike, especially in the summertime (Fig. 4) (Stolz, Köstler 2003: 38).

The area occupied by Haidplatz is about three times smaller than that of Campo Square and some striking qualitative differences between the two places are clear. Haidplatz houses medieval buildings as well as the "Golden Cross" (das goldene Kreuz) with its battlement, which has lodged kings and queens and princes from medieval times. The three-story four-wing terracotta construction named "die neue Waag", built in 1441, the Arch building, Thon-Dittmer-Palais, and the Justitiabrunnen are all situated in this square (Stolz, Köstler 2003: 39; Trapp 2008: 122-125).
As Carr believes, providing people with opportunities to experience a range of temporal and spatial rhythms is considered to be one of the practical suggestions for improving a city's form and making it more responsive (Carr 1978: 159). This fact is considered more in detail in what follows. Both Campo Square and Haidplatz are now analyzed using a range of sensory stimuli, including sight, touch, aural and olfactory stimuli. In addition, they will be regarded from the point of view of the simple and protective qualities of inhabited space.

\section{Association of all senses}

\section{Sense of sight}

Campo Square is classified more as a social and ceremonial square than as a religious or residential square or a square with street shopping potential. Our wonderful experiences in Campo Square do not stem from confrontation with a natural environment. There is not much green space on offer in the square. The varying heights of surrounding buildings, varying colors, the proportion between the area of open square and the height of the surrounding buildings, the sloping site of the square, the density of people in the radiating narrow shaded streets, and the separation of people in the open and bright square are some of the main visual stimulations in this place (Fig. 5).

Campo Square is a comprehensive place when it comes to people's orientation in relation to different visual landmarks. People not only sit in one place, around the fountain, but are scattered in every corner: around the fountain, children playing on the slope of the square, people sitting in the shadow of the clock tower or in cafes, people gathering on the balcony of the building lo-
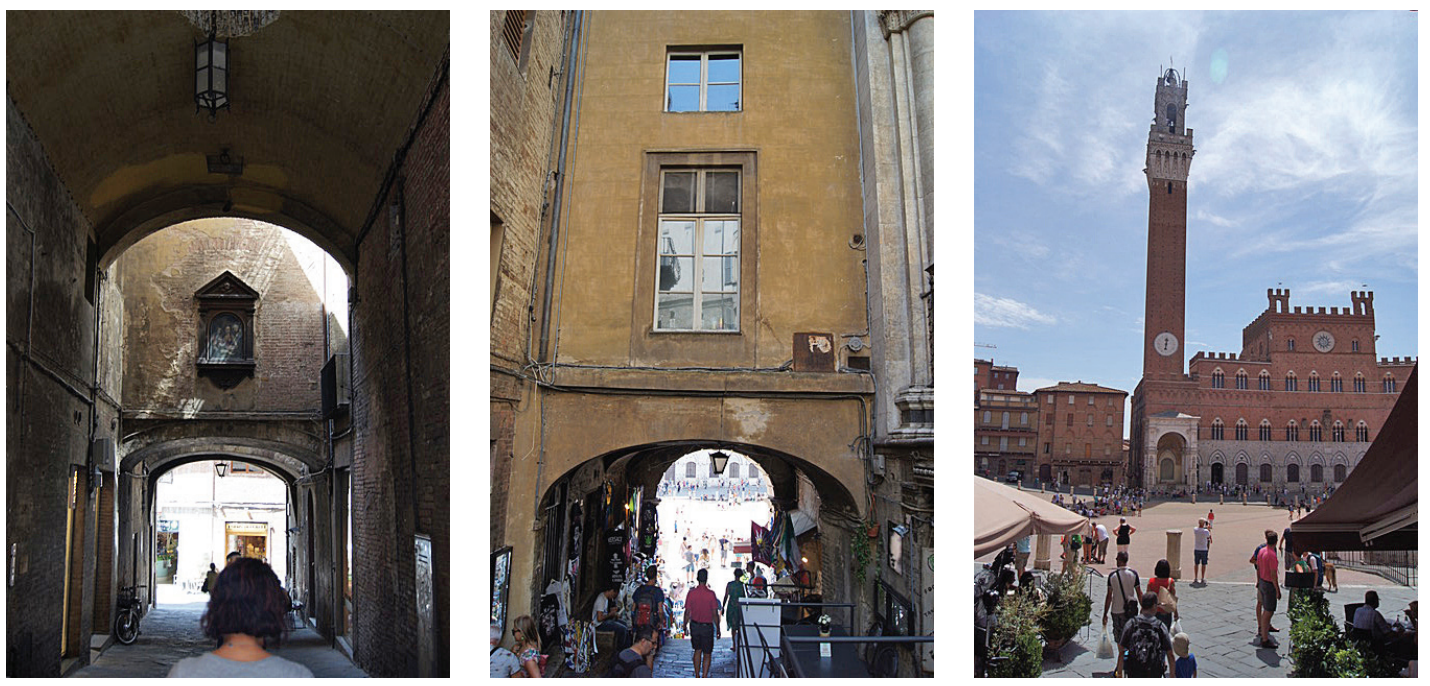

Fig. 5. Different views on the way to Campo Square from the northwest. The contrast between shaded streets and the open public square is clear, affording attraction and enthusiasm toward the open space. Photo courtesy of the author. 

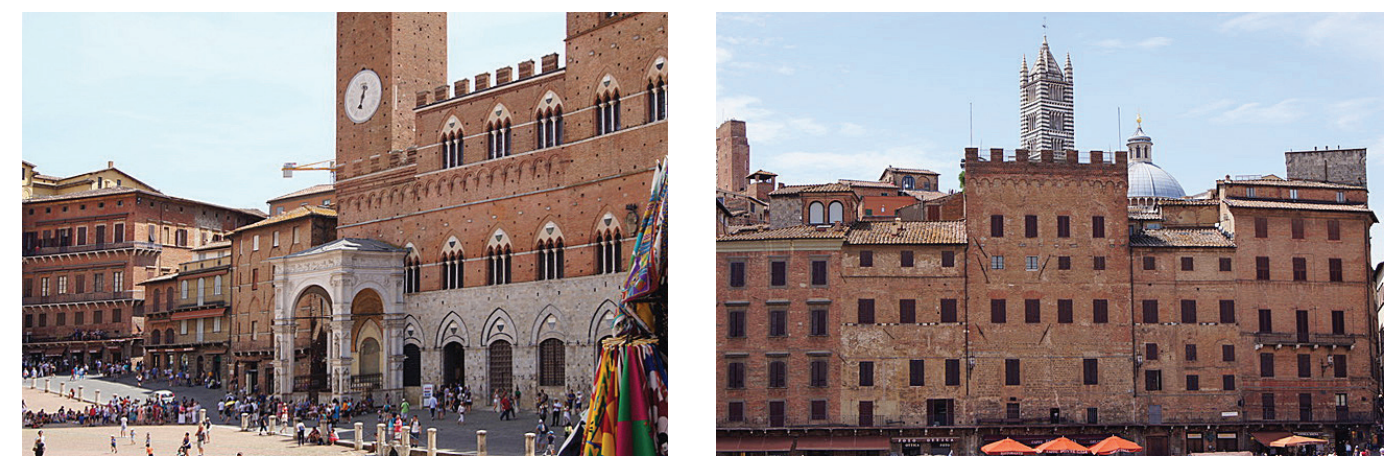

Fig. 6. Right: Siena Cathedral, a main landmark, is visually accessible from the southeast side of Campo Square. Left: View of the Town Hall. Photo courtesy of the author.
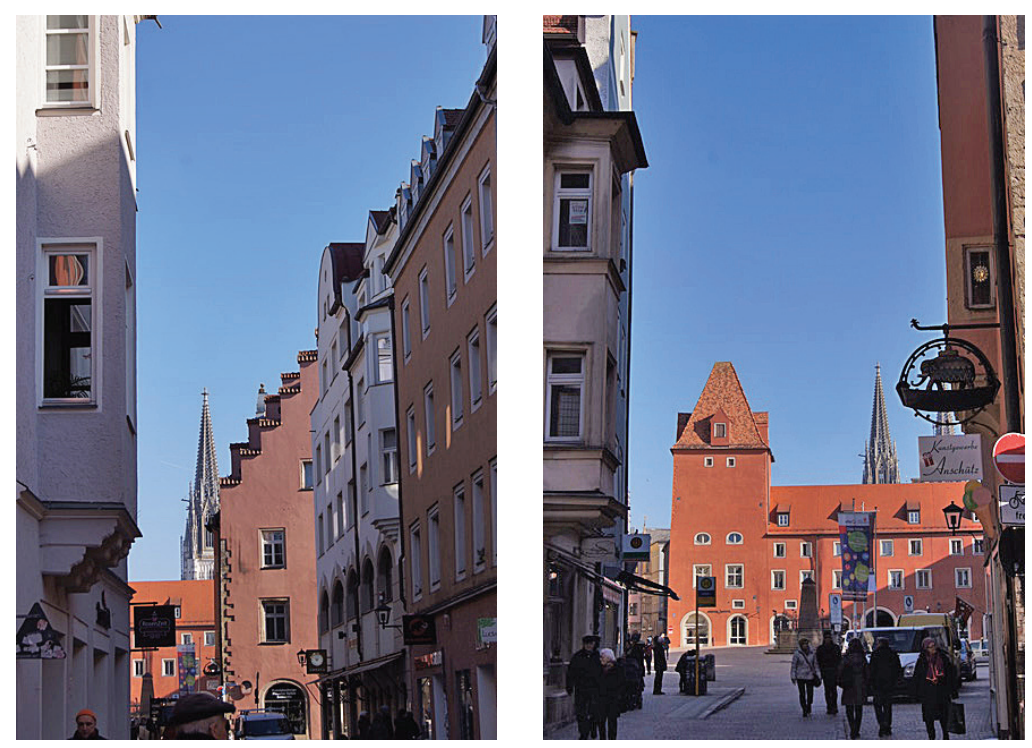

Fig. 7. Views on the way to the Haidplatz from the west. No clear contrast exists between the shaded streets and the open public square. Regensburg Cathedral as a main landmark is visually accessible from the west side of Haidplatz. Photo courtesy of the author.
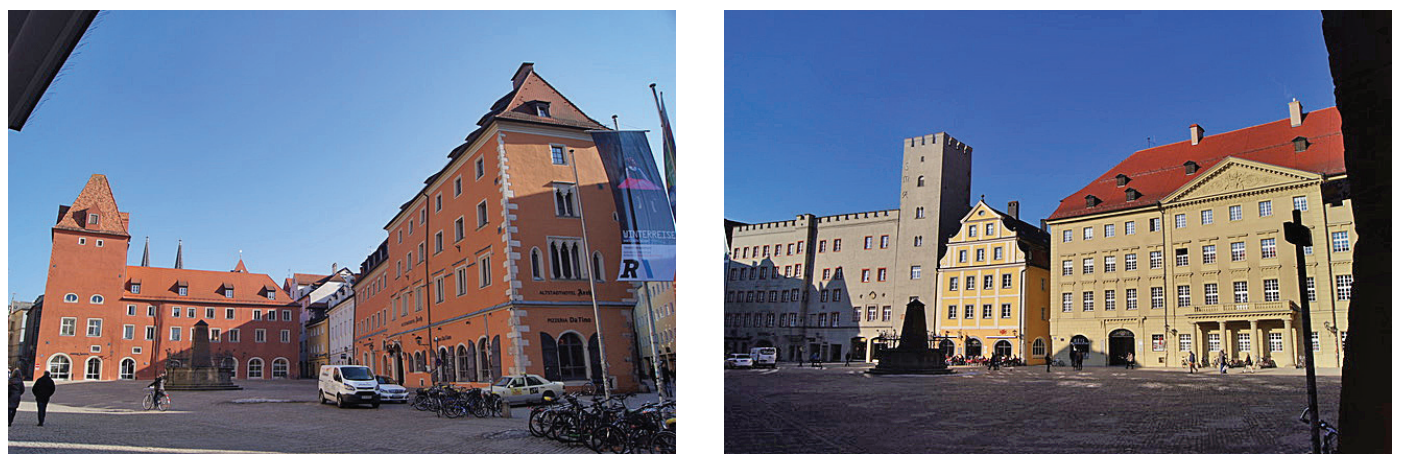

Fig. 8. Haidplatz. The current square is a mixture housing different buildings, most of them dating from the medieval and the Renaissance. Left: die Neue Waag: the medieval terracotta building and one part of the Arch building. Right: the Thon Dittmer Palace and the golden Cross with its seven-story medieval tower. Justitia Fountain is situated in the middle of the square and is protected in cold autumns and winters within a wooden cover. Photo courtesy of the author. 


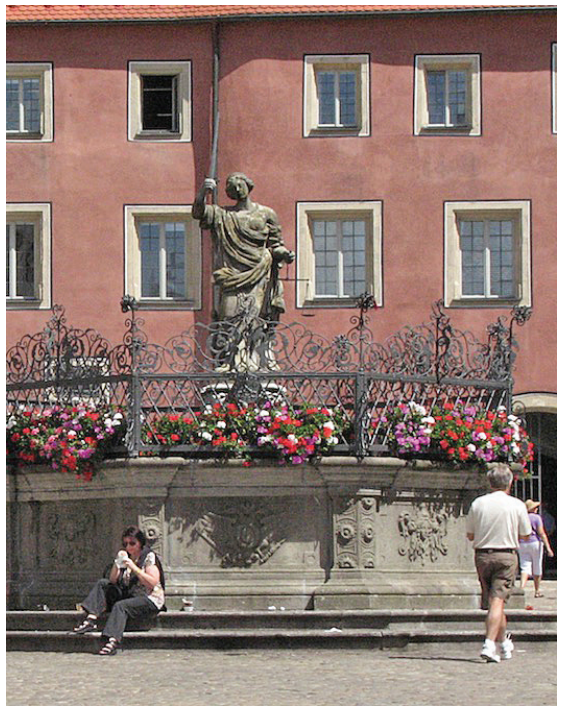

cated in the northeast of the square, resting or watching events below ${ }^{4}$ (Fig. 6). The monumental fountain (the Fonte Gaia), with its location in front of the Palazzo Pubblico (the Town Hall), makes for a strong symmetrical axis and, consequently, a very strong visual experience in the square. According to Kostof (1991), "the brick tower of the city hall lifts its attenuated shaft from the floor of the Campo to respond to the white mass of the cathedral and its campanile on the hilltop of Citta" (Kostof 1991: 296).

Haidplatz, on the other hand, with its triangularshaped square, is surrounded by colorful renovated medieval buildings (Schultheiss 2006: 67). Despite its smaller scale, it is well known as a special social square in Regensburg (Fig. 7). By hosting special occasions as well as a few musical events and a Christmas market, and in addition due to the location of both the city library within the Thon Dittmer Palace, a cultural building, and the Golden Cross hotel and restaurant, this square reflects an important sociocultural intersection for both inhabitants and visitors.

The experience of place in Haidplatz is influenced mostly by visual attractions. In comparison to Campo Square, there is no strong contrast between shaded narrow streets and the open square. Except for the vertical towers of the golden Cross and die neue Waag buildings in Haidplatz, there is no strong focal point and no dominant axis (Fig. 8).

\footnotetext{
4 Based on Nasar's experiment on the effects of a few characteristics on the livability of a public place, the combination of seats and sculpture had higher scores than either element alone, the ratings also indicated that sittable space had the largest effect (Nasar 2016: 14).
}

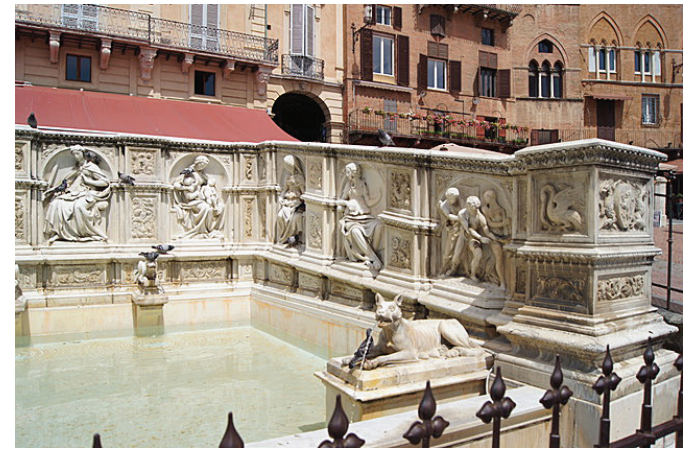

Fig. 9. left: Justitia Fountain, Haidplatz, in Summer. Right: Monumental Fountain (Fonte Gaia), Campo square. Photos courtesy of the author.

\section{Sense of touch}

There are features in Campo Square - the selection of materials of its surrounding buildings, the redbrick paving of the square, separated with lines of travertine, the contrast between the heat of the square in the summertime and the coolness of shadowed narrow streets, the water, the monumental fountain of Fonta Gaia ${ }^{5}$ with its marble panels - which provide an atmosphere embued with both provocations and stimulations (Fig. 9). On the other hand, in Haidplatz, the selection of cement materials for the colorful facades of surrounding buildings and the stone paving unfold another character altogether. The so-called Justitiabrunnen (Justitia Fountain and its statue) is situated in the middle of the square and is protected in cold winters within a wooden cover. The fountain is considered to be a central point in the square, which makes it a stop for many visitors, its stairs offering a place for sitting or providing a play area for children. The Justitia statue is visually accessible and readable for visitors; however due to the height of the surrounding octagonal pool walls, it cannot be touched and felt.

\section{Sense of aural}

Different sounds can be heard in Campo Square: the sound of crowds, mostly tourists during the day in the square and in restaurants; the sound of the bell tower of the square; sound of the cathedral's bell located on the west side; the sound of children playing in the square after school; the sound of water running in the fountain;

\footnotetext{
5 Fonta Gaia is considered as an example, which is distinguished in displaying the beginnings of the transformation of fountains into ornamented public monuments in the later Middle Ages (Kostof 1991: 266).
} 

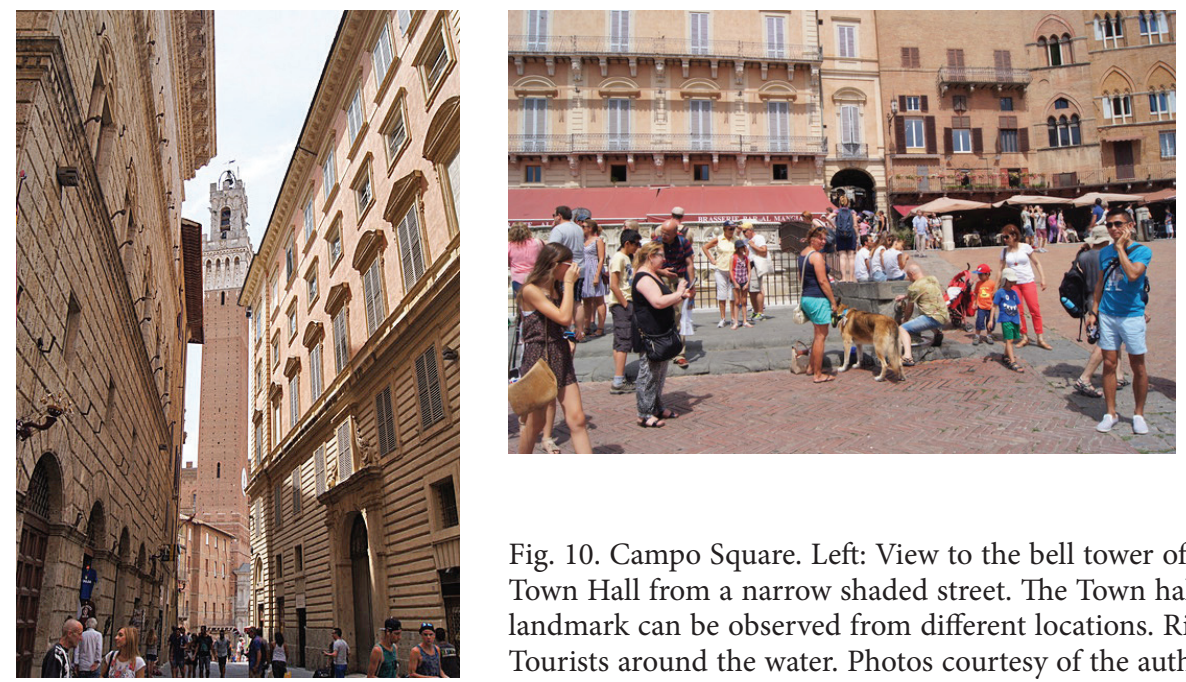

Fig. 10. Campo Square. Left: View to the bell tower of the Town Hall from a narrow shaded street. The Town hall as a landmark can be observed from different locations. Right: Tourists around the water. Photos courtesy of the author.
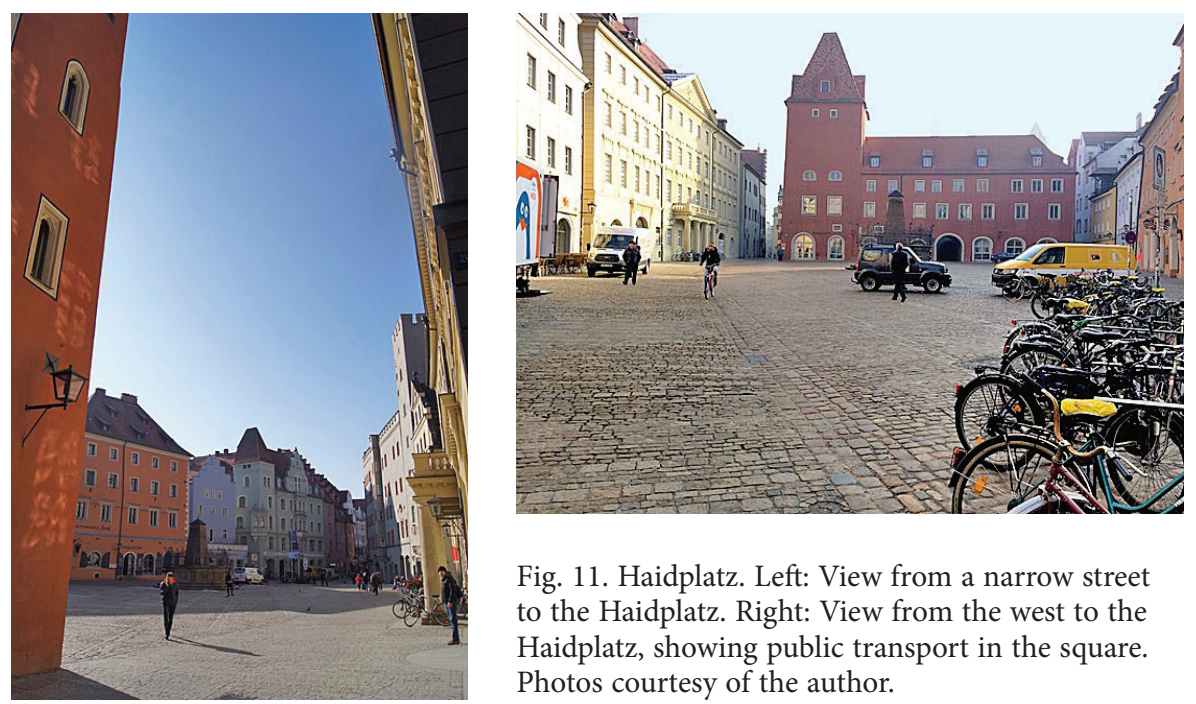

Fig. 11. Haidplatz. Left: View from a narrow street to the Haidplatz. Right: View from the west to the Haidplatz, showing public transport in the square. Photos courtesy of the author.
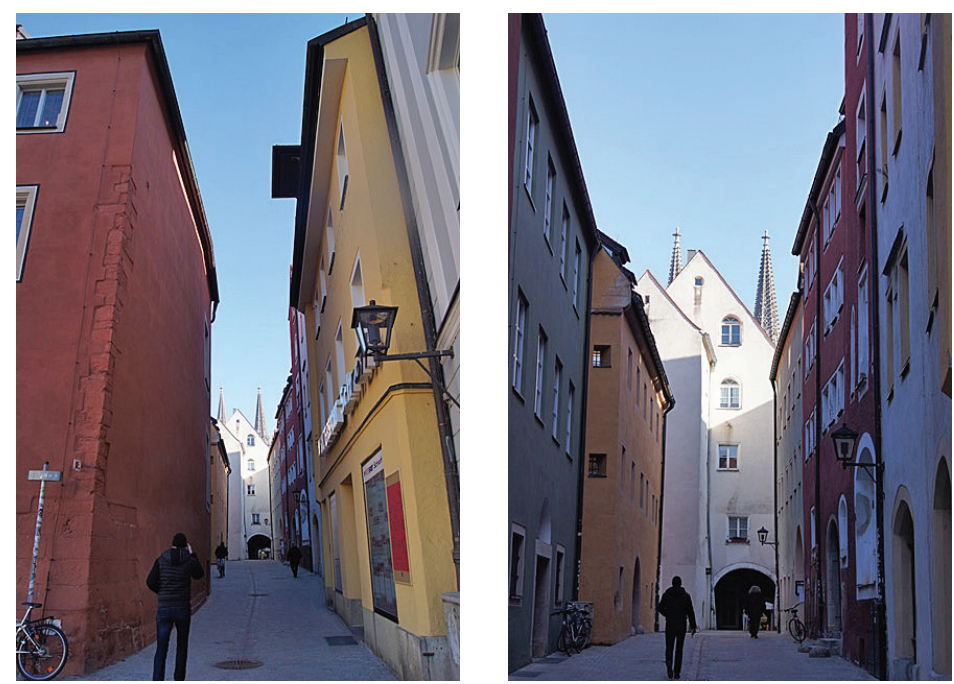

Fig. 12. Haidplatz. narrow shaded streets radiating from the square with views to the towers of the Regensburg cathedral. Sense of visual and aural. Photos courtesy of the author. 

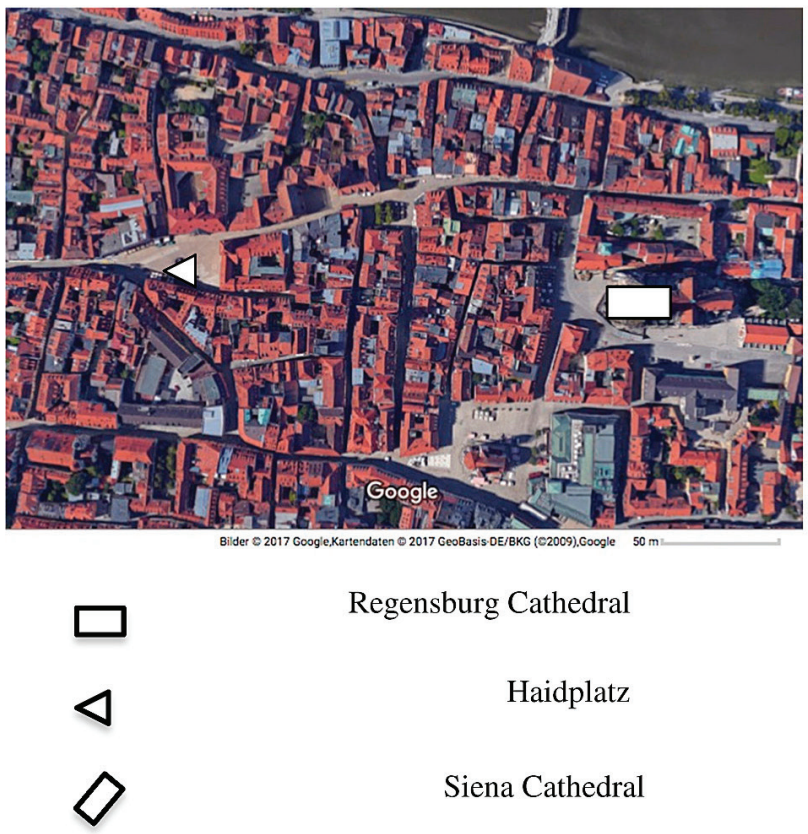

0
Regensburg Cathedral

Haidplatz

Siena Cathedral

Campo square

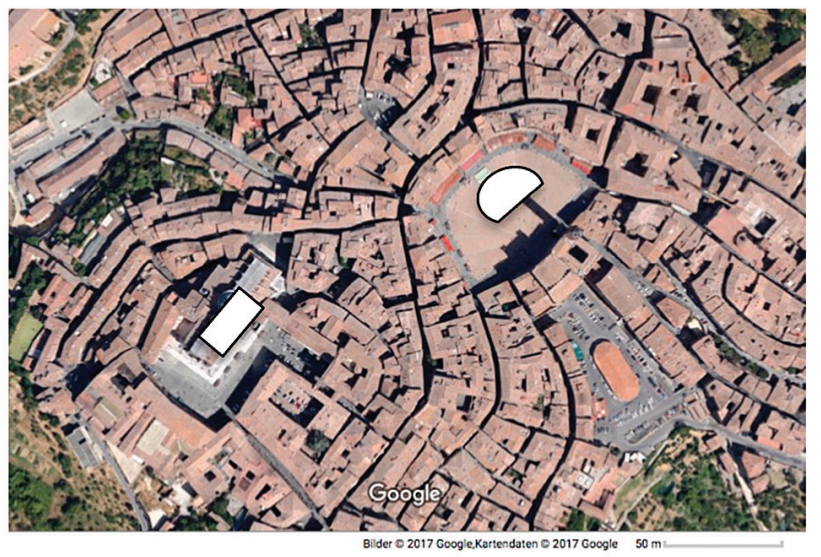

Fig. 13. Left: The location of Haidplatz in relation to the cathedral () 2017 Google, Maps data (c) 2017 Geobasis-

DE/BKG). Right: Campo Square, the way from the square to the cathedral is less than the distance between Haidplatz and Regensburg cathedral. (c 2017 Google, Maps data (C 2017 Geobasis-DE/BKG). and the sounds of merchants leaving their shops at nights. These are the main features which affect our sense of the aural (Fig. 10).

On the other hand, in Haidplatz, the sound of water cannot be heard. The square is only loud and crowded during special summer or winter occasions such as theater performances, city celebrations, a jazz festival or Christmas market, when it would be full of life (Stolz, Köstler 2003: 38). Public transport, which is allowed in the old town of Regensburg as well as in Haidplatz, causes additional noise (Fig. 11).

The distance between the square and the cathedral is another determinant in relation to aural stimuli. The distance between Siena Cathedral and Campo Square is less than the distance between Regensburg Cathedral and Haidplatz. This fact influences the amount of sound and density of people in Campo Square (Figs 12, 13).

\section{Sense of olfactory}

In Campo Square, olfactory stimulations evoking images of rest and which reinforce the wider sensual experience originate from cafes and restaurants in the square itself and also from various establishments located in the shaded narrow streets which radiate out from the square. (Fig. 14).
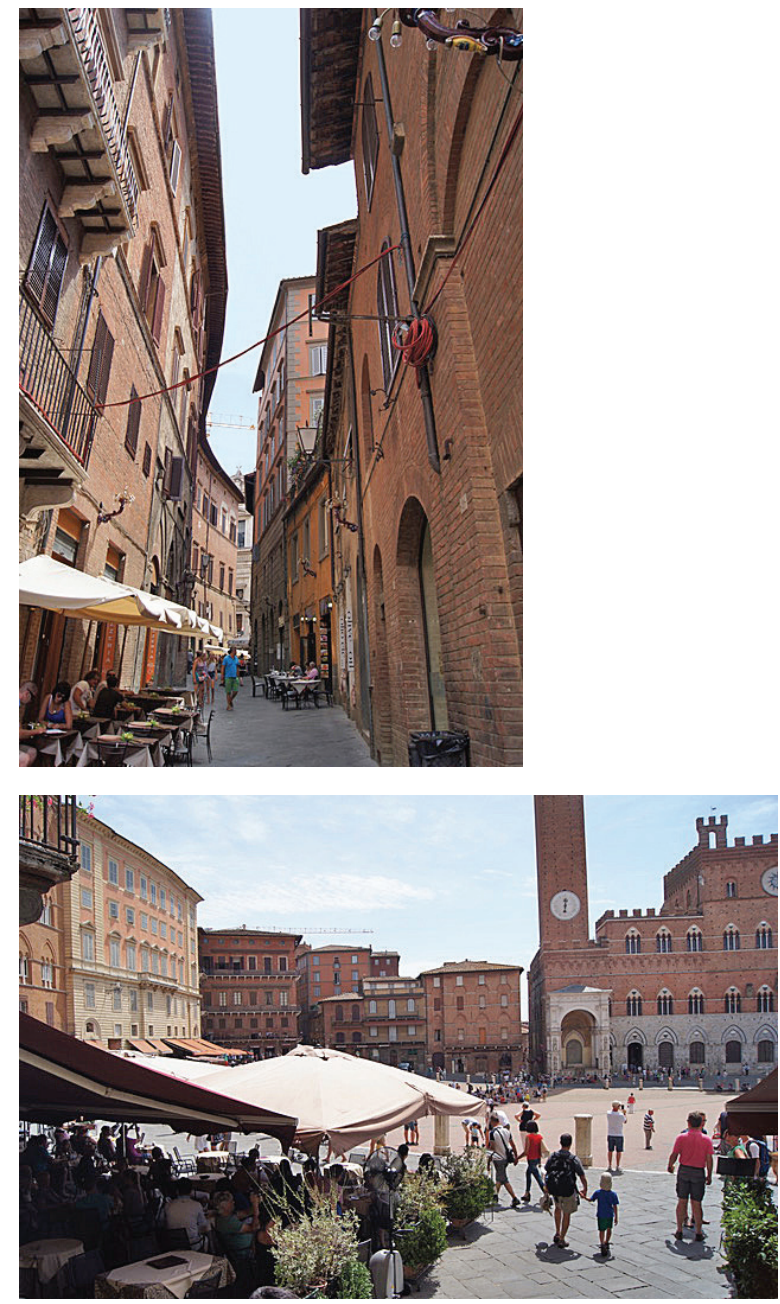

Fig. 14. Campo Square. Cafes and restaurants around the square. Photos courtesy of the author. 

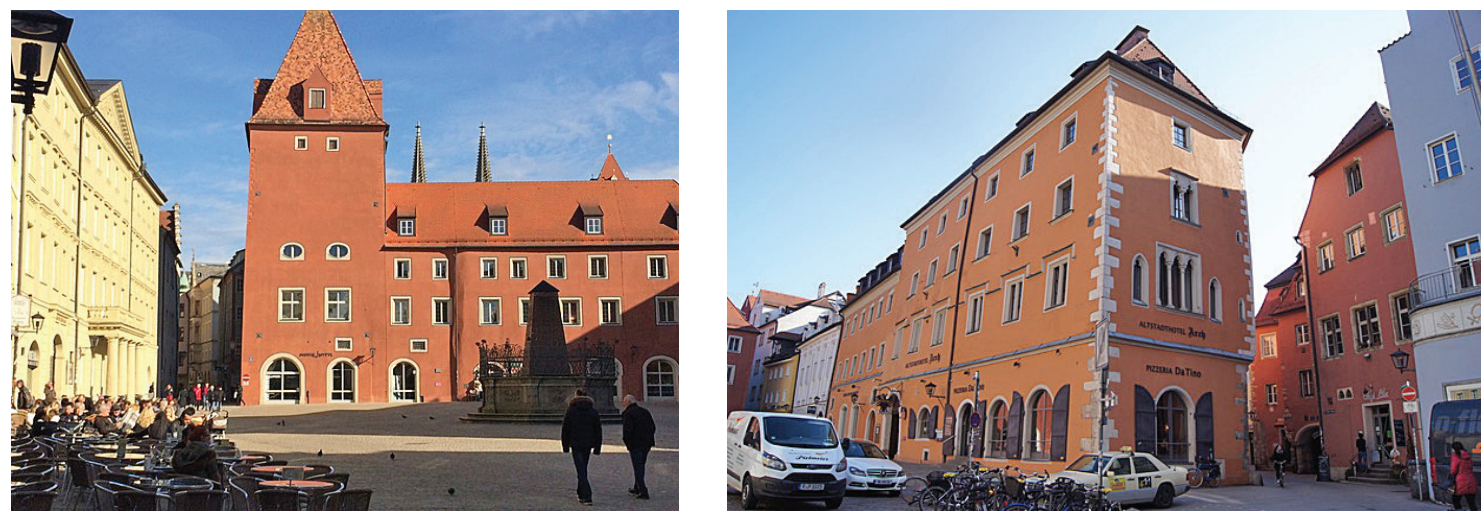

Fig. 15. Haidplatz. Left: Outdoor restaurant in front of the golden Cross. Right: The historical "Arch" building serves as a hotel but does not offer outdoor seating in winter. Photos courtesy of the author.
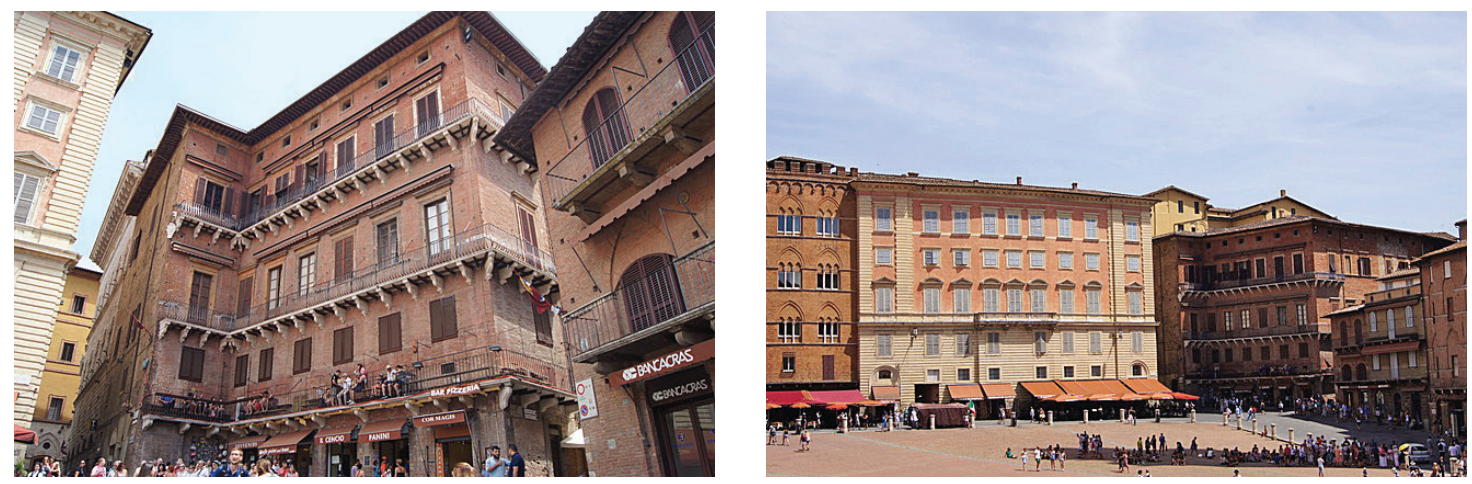

Fig. 16. The images of simplicity in the Campo Square. Left: A narrow street radiated from Campo Square; here the balconies of the three-story building offer opportunity for rest. Right: Image of rest; people benefiting from the shadow of the bell tower. Photos courtesy of the author.

In Haidplatz, however, due to cold weather, cafes and restaurants are mostly located inside hotels within the buildings that surround the square. The exception is the restaurant of the Golden Cross building, which offers outdoor seats most of the year. In summertime the square becomes more important as a gathering and meeting place (Fig. 15).

\section{The simple and protective qualities of inhabited space}

The inhabited space which is considered far from any picturesqueness, possesses two significant qualities in Bachelard's thought: "protection" and "simplicity", which support each other and provide the basis for promoting our imagination. Bachelard believes that images of simplicity are accompanied by the values of intimacy as well as of security, sincerity, and rest. In order to create real images, Bachelard goes in the di- rection of maximum simplicity (Bachelard 1994: 107). "The more simple the engraved house, the more it fires my imagination as an inhabitant. Its lines have force and, as a shelter, it is fortifying. It asks to be lived in simply with all the security that simplicity gives" (ibid.: 50). Bachelard believes that spaces should let inhabitants dream and imagine; in this sense, they possess simple and protective qualities and, consequently, they project other qualities of security, sincerity, and rest: "whenever life seeks to shelter, protect, cover or hide itself, the imagination sympathizes with the being that inhabits the protected space" (ibid.: 132). Our power of imagination is able to facilitate how we perceive our space: the more our imagination is evoked and stimulated, the deeper we feel, experience, live, and perceive it (NoorMohammadi 2015: 73). Based on this overview we can now turn to the images of simplicity and protection in Campo Square and Haidplatz. 

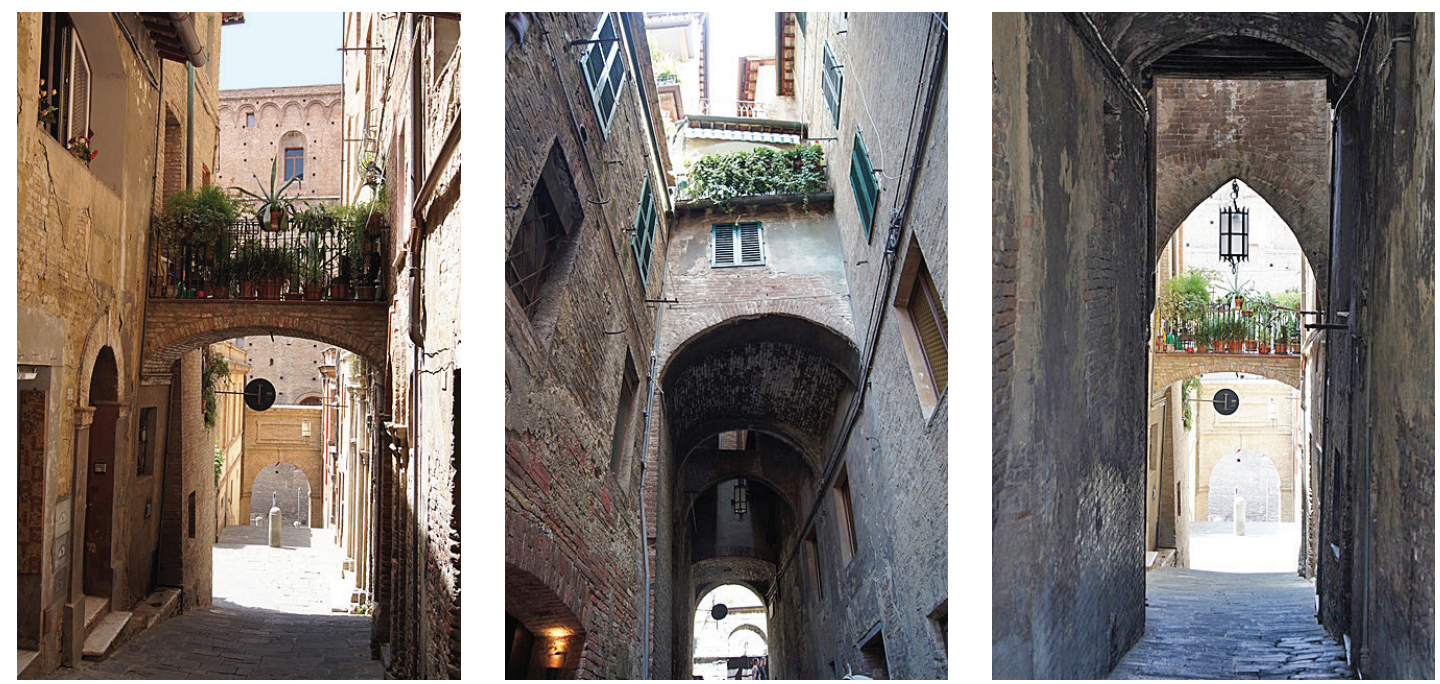

Fig. 17. Images of simplicity in the streets radiating from Campo Square, reflecting images of rest and security. Photos courtesy of the author.
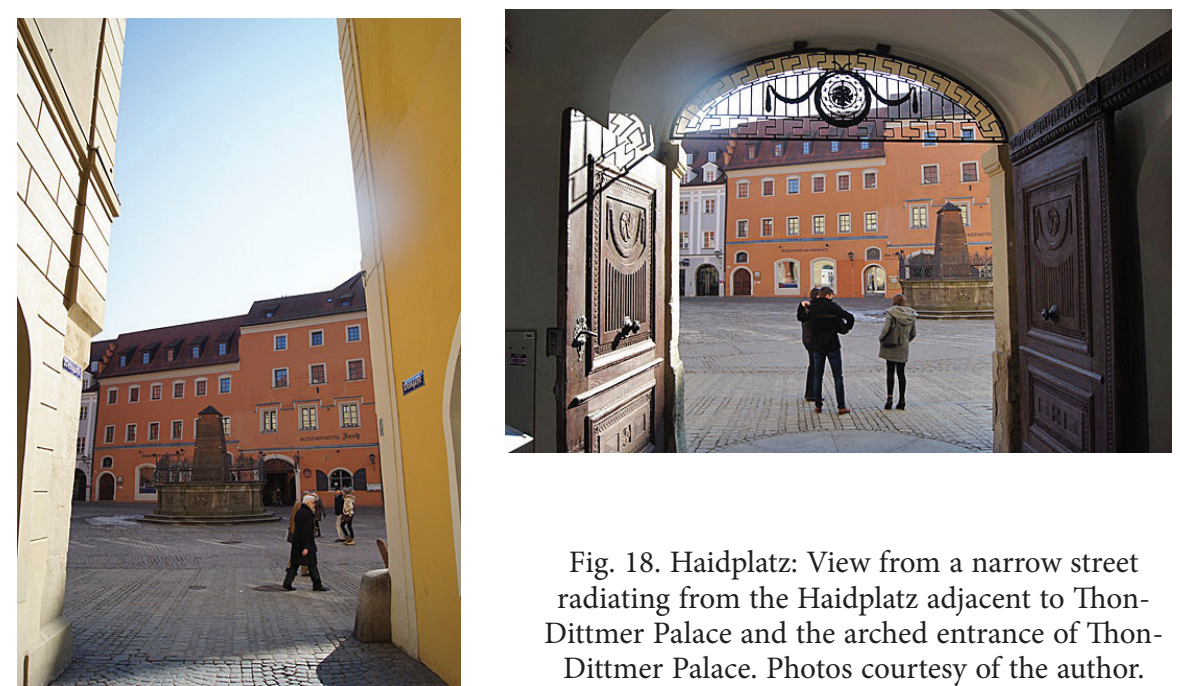

Fig. 18. Haidplatz: View from a narrow street radiating from the Haidplatz adjacent to ThonDittmer Palace and the arched entrance of ThonDittmer Palace. Photos courtesy of the author.

\section{Image of simplicity}

Simple and protective spaces in the example of Campo Square parallel the association of all of our senses, enhance the power of imagination and provide a context in which to imagine, daydream, feel, live, experience, and perceive.

The image of simplicity in this square is not only reflected through the visual influence of the physical forms of the surrounding buildings; rather, it is offered to provide flexibility and freedom for people when making their selections of places in which to rest (Fig. 16). In addition, one is not overloaded visually through the use of too many ornaments on the surrounding buildings or too many commercial advertisements, as in some modern squares. Images of rest can be even analyzed by walking through shaded narrow streets decorated with green areas (Fig. 17).
In Haidplatz, the image of simplicity is not limited to the simple facades of surrounding buildings, but is also dependent on other qualitative factors. The shaded entranceways leading to the triangular shape of Haidplatz cause a sense of enthusiasm. However, in comparison with Campo Square, the proportions between the widths of the radiating streets from Haidplatz and the area of the square itself are not as striking, and so the open and mass spaces in Haidplatz do not create as strong a contrast (Figs 7, 18).

\section{Image of protection}

The sense of protection in Campo Square is most of all created through its geometrical shell shape, which is surrounded by four- and five-story buildings that are mostly red in colour. The thick brick walls reflect a sense of protection and do not offer transparency and too much open- 

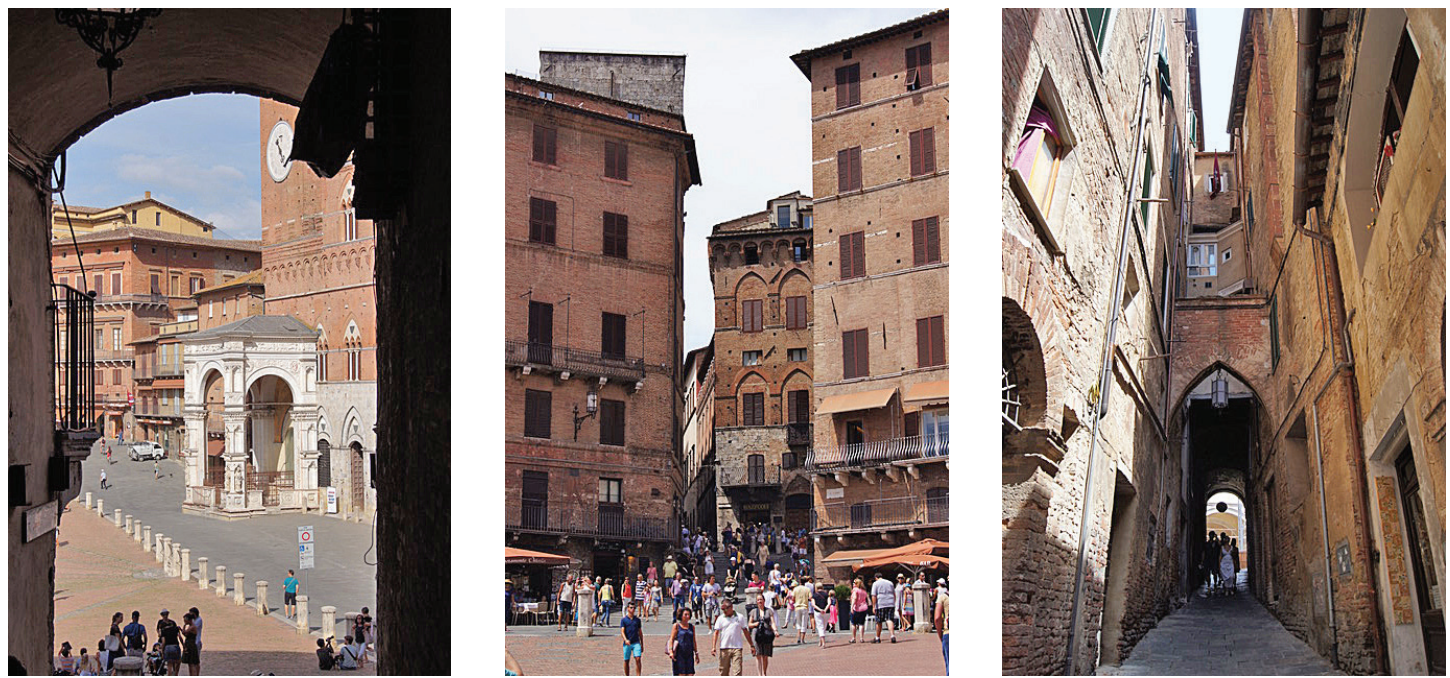

Fig. 19. Walking through various shaded narrow streets towards the Campo Square is accompanied by a sense of secrecy. Photos courtesy of the author.
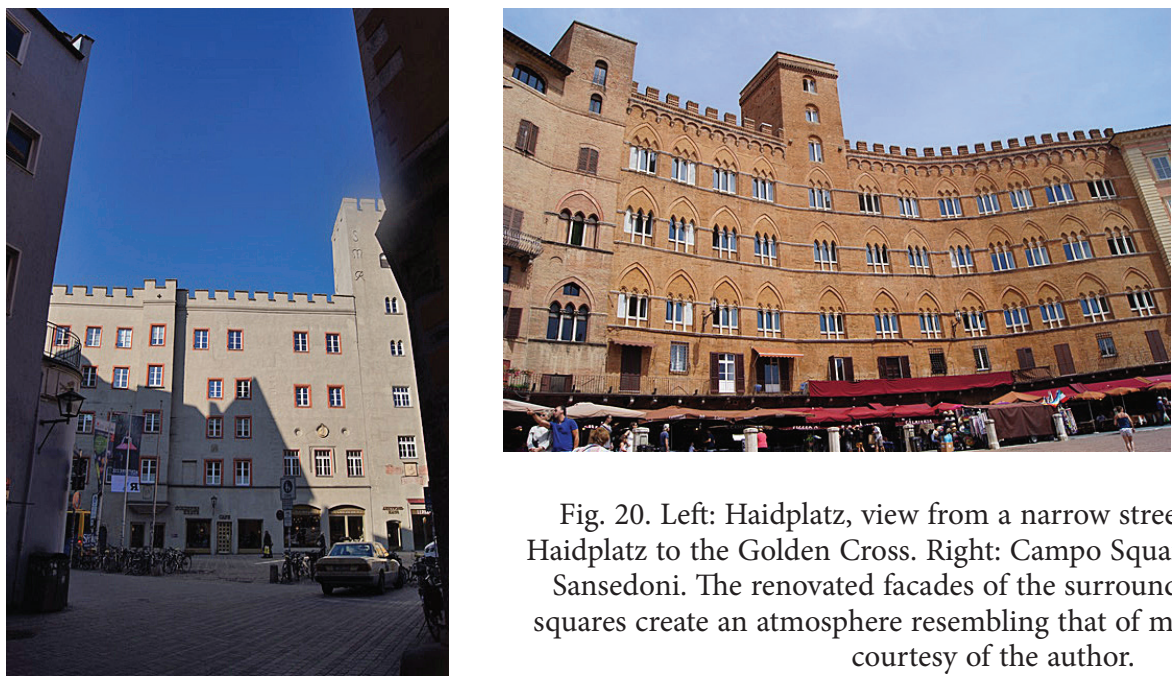

Fig. 20. Left: Haidplatz, view from a narrow street radiating from the Haidplatz to the Golden Cross. Right: Campo Square, View to the Palazzo Sansedoni. The renovated facades of the surrounding buildings of two squares create an atmosphere resembling that of medieval castles. Photos courtesy of the author.

ness. At first glance, openings in the facades of the buildings are not obvious and the buildings are harmonious in scale, proportion, materials, and color. The only different building is the Town Hall with its tall bell tower. However, this building is not located separately, as are many other splendid palaces in historical squares; rather, it is harmonious with the adjacent buildings as evidenced through its simple and clear architecture. The contrast between the public space of Campo Square and the private spaces of the narrow shaded adjacent streets is also strong. Various shaded narrow streets radiating from the square provide multidimensional emotional functions as well as rest, secrecy, and enthusiasm (Fig. 19).
Lynch states that "A good environmental image gives its possessor an important sense of emotional security. He can establish an harmonious relationship between himself and the outside world". He goes on to say that "a distinctive and legible environment not only offers security but also heightens the potential depth and intensity of human experience" (Lynch 1978: 153). In comparision with the shell shape of Campo Square, the triangular shape of Haidplatz holds less attraction. However protected by closed medieval surrounding buildings, Haidplatz is not as well emotionally protected as Campo Square. Except when passing through the narrow radiating streets from Haidplatz, one does not experience a sense of security and protection (Fig. 20). 


\section{Experience of place in Campo: intertwinement between sensory realm and inhabited images}

The experience of place is a multidimensional process influenced by the intertwinement of physical and social activities with the psychological-emotional reflections of the built environment. Based on Canter, activities and physical forms are amalgamated in the experience of place (Canter 1977: 1). Castello based on Canter's statement concludes: "Place would be a socio-physical unit of environmental experience, forming an eco-behavioural pattern in the environment" (Castello 2010: 4). But as Castello states "people feel better in certain spaces" (ibid.: 2). In addition, he distinguishes places "which are qualified by evoking people's collective memory of the phenomena of the surroundings, evoking the historical formation of their town, forms constructed according the prevailing architectural patterns of different historical periods, and evoking legends which after all result from phenomena of memory stimulated by elements of the local temporal collective imagination" (ibid.: 10).

Physical aspects in Campo Square include harmonious architectural forms and elements of a place such as warm colors, height, and density of buildings and geometrical and proportional dimensions, as well as centralization, direction and rhythm, and additional topographical aspects. ${ }^{6}$ Sociocultural aspects including the historical style of buildings, social life, customs, lifestyles, and values, and interrelations between inhabitants of the neighborhood, merchants and tourists, characterize and identify the atmosphere of a place. Moreover, emotional-psychological aspects as well as memory, imagination, and their entwinement with our sensory realm are considered significant in the creation of strong personal attachment to place. This experience does not only stem from contrasts between shadow and sun, and density of mass and open space. It is not limited to the flexibility of locations of seats and the sound of water. Visual, aural, tactile, and olfactory experiences are amalgamated so elaborately in this square, that one enjoys not only being present in public zones along with other people, but also being in private secure and rest spaces.

The images of inhabiting in the example of Campo Square function in order to transcend our sensory realm. According to Bachelard, we encounter a high degree of intimacy and intensity in our experience in Campo Square. The distinctive, strong, and lovely qualities of Campo Square are not only the result of the visual impact of its surrounding buildings, with

\footnotetext{
6 According to Kostof, "At the Tuscan city of Siena the initial settlements were hilltop communities. These similar topographic circumstances yielded parallel results in terms of urban form: the low saddle of land between two of the original settlements became the site of Siena's central square, the Campo" (Kostof 1991: 61).
}

their architectural values; this place is not splendid in scale; Campo Square does not possess an authoritative significance, and it is not surrounded by magnificent and monumental buildings. Relph, impressed by Robert Goodman, says that "the more magnificent and monumental the official public places, the more trivial becomes the citizen's personal environment, and the more he tends to be awed by the official environment" (Relph 1976: 35). The intertwinement of our physical, sociocultural, and emotional experiences with a high degree of intimacy and intensity leads to the reflection of certain meanings in Campo Square. As Pallasamaa (1996) believes, meaning lies not in forms but in the images transmitted by the forms and the emotional force that they carry (Pallasamaa 1996: 449).

Our experience in Haidplatz, however memorable, cannot be considered to be as influential as Campo Square. Walking to and through Haidplatz, however striking and genuine, does not let one to dream beyond the sensory realm. It is wonderful to imagine that queens and kings 500 years ago may have been hosted by the Golden Cross building, and that this building and its neighbors still continue to host tourists today (Trapp 2008: 123). The visual images of the colorful buildings that surround Haidplatz take our memories back to medieval times, but except for the arched entrance of the Thon-Dittmer Palace, the closed facades are not welcoming. The shape of the square does not offer centrality and the proportion between the square area and the height of the surrounding buildings does not make for a strong image of protection. We cannot explore any strong contrasts between public open space (Haidplatz) and different private spaces of enclosure, security, secrecy, quiet, rest, and silence. Except for a few spaces and the narrow adjacent streets, no different inbetween spaces as semi-public places exist. Our feelings and experiences in Haidplatz are created from monotone albeit pleasant images.

\section{Conclusions}

The main hypothesis and objectives of this paper aimed to show how the contribution of Bachelard's topoanalysis provides a strong basis for the interpretation of architectural and urban environments. The distinctive communal-gathering character of Campo Square in Siena allows people to make strong connections between the place and their personal lives, as well as their memory and imagination. The different qualitative aspects in the creation of distinctive and strong qualities in Campo Square have been analyzed in their connection to the lived and inhabited images embedded in Campo Square. In comparison to Haidplatz in Regensburg, real and inhabited images in Campo Square come to be imagined, remembered, perceived, and interpreted, and this provides strong attachment to Campo Square in relation to its associative meanings. The interrelation between memory 
and the imagination provides us with a powerful means with which to perceive our environment. We feel better in certain places, as they possess real and inhabited images. Our imagination engraves the inhabited images on our memory. This process helps to promote our imagination in perceiving Campo Square and in strengthening our attachment with it. Inhabited space, with its simple and protective qualities, is not necessarily imagined in every place; rather, similar to the significant example of Campo Square, the reciprocity between the sensory realm and inhabited images makes our experiences in this place intense and creates a memorable character.

This paper signifies Bachlerad's topoanalysis and applies his contribution to the interpretation of architecturalurban environments through the following interrelated and connected approaches:

1) Analysis of the interrelations between sociocultural norms and physical aspects of built forms.

2) Analysis of our sensory realm in confrontation with the built environment.

3) Analysis of images of inhabiting: images of simplicity and protection as well as of enclosure, security, secrecy, quiet, rest, and silence.

4) The reciprocity between our sensory realm and images of inhabiting.

Campo Square is an example of an inhabited space in which, Bachelard believes, inhabitants can dream and imagine. The overlap between physical and sociocultural factors and psychological-perceptual aspects in Campo is significant, leading to the creation of an authentic character. A consideration of topoanalysis in an interpretation of urban-architectural environments might help us to rethink how attachments to place and their contribution to our sense of meaning can be phenomenologically interpreted. This paper posits that we need to know more about a phenomenological interpretation of our experiences by confronting an architectural urban place. This would constitute developing new interpretative qualitative and quantitative tools in order to analyze more comprehensively our imaginations and perceptions when confronting the meanings associated with an architectural-urban place. This approach does not deny other methodologies; rather, suggests parallel quantitative researches in the future. These could include researches based on survey and interview methods with users of the square, or a study based on the behavioral settings in the mentioned squares.

\section{Acknowledgment}

This paper is the result of independent study carried out during a period of parental leave.

\section{References}

Bachelard, G. 1971. On poetic imagination and reverie. Translated by Colette Gaudin. New York: Bobbs-Merrill.

Bachelard, G. 1994. The poetics of space. Translated by Maria Jolas. Boston, MA: Beacon Press.

Benevolo, L. 1983. Die Geschichte der Stadt. Frankfurt am Main: Campus Verlag.

Canter, D. 1977. The psychology of place. Architectural Press.

Carr, S. 1978. Some criteria for environmental form, Chapter 6 in S. Kaplan, R. Kaplan (Eds.). Humanscape: environments for people. Belmont: Wadsworth publishing Company, pp. 156-159.

Casey, E. S. 1998. The fate of place: a philosophical history. Berkeley: University of California Press.

Castello, L. 2010. Rethinking the meaning of place: conceiving place in architecture-urbanism. Surrey: Ashgate Publishing Limited.

Hennig, Ch. 2005. Mittelitalien. Ostfildern: DuMont Reiseverlag.

Kostof, S. 1991. The city shaped: urban patterns and meanings through history. London: Thames and Hudson Ltd.

Leach, N. (Ed.). 1997. Rethinking architecture: a reader in cultural theory. London and New York: Routledge.

Lynch, K. 1978. The image of the environment, Chapter 6 in S. Kaplan, R. Kaplan (Eds.). Humanscape: environments for people. Belmont: Wadsworth publishing Company, 150-155.

McGuffin, D. 2002. Siena's Grand Square [online], [cited 1 December 2015]. Available from Internet: http://blog.davidmcguffin.com

Moosburger, U.; Morsbach, P. 2009. Regensburg und Europa im Mittelalter: Wege der Architektur. Regensburg: Fredrich Pustet.

Nasar, J. 2016. Behavior settings, affordances, and environmental preference, IAPS - Bulletin of People-Enviromental Studies 44(Autumn): 12-16.

Nevola, F. 2007. Siena: constructing the Renaissance City. New Haven und London: Yale University Press.

NoorMohammadi, S. 2015. The role of poetic Image in Gaston Bachelard's contribution to architecture: the enquiry into an educational approach in architecture, The Journal of the International Association for Environmental Philosophy 12(1): 67-85.

Otero-Pailos, J. 2010. Architecture's historical turn: phenomenology and the rise of postmodern. Minneapolis, London: University of Minnesota press.

https://doi.org/10.5749/minnesota/9780816666034.001.0001

Pallasamaa, J. 1996. The Geometry of feeling: a look at the phenomenology of architecture. Transcribed, in K. Nesbit (Ed.). Theorizing a new agenda for architecture. An anthology of architectural theory 1965-1995. New York: Princeton Architectural Press, 447-453.

Relph, D. 1976. Place and placelessness. London: Pion.

Seamon, D. 1996. A singular impact: Edward Relph's place and placelessness' [online], [cited 14 February 2016], Environmental and Architectural Phenomenology Newsletter 7(3): 5-8. Available from Internet: http://www.arch.ksu.edu/ seamon $/ 21 \% 2096 \% 20$ fall $\% 207 \% 203$.pdf

Sedlmeier, A.; Vossen, J.; Maag, K. 2006. Stadtatlas Regensburg. Regensburg: Friedrich Pustet.

Steves, R. 2013. Hill Towns of Central Italy (Snapshot). Avalon Travel Publishing. 
Stolz, H.; Köstler, T. 2003. Regensburg aus der Luft. Regensburg: Friedrich Pustet.

Trancik, R. 1986. Finding lost space: theories of urban design. John Wiley \& Sons.

Trapp, E. 2008. Welterbe Regensburg. Regensburg: Schnell \& Steiner GmbH.

Ujang, N.; Zakariya, Kh. 2015. The notion of place, place meaning and identity in urban regeneration, Procedia - Social and Behavioral Sciences 170(27): 709-717. https://doi.org/10.1016/j.sbspro.2015.01.073

Van Manen, M. 2014. Phenomenology of practice: meaning-giving methods in phenomenological research and writing. Walnut Creek, CA: Left Coast Press.

Vesely, D. 2004. Architecture in the age of divided representation. Massachusetts Institute of Technology.

Zimmermanns, K. 2011. Toscana: Das Hügelland und die historischen Stadtzentren. Dumont Reiseverlag.

\section{SUSAN NOORMOHAMMADI}

Born and raised in southern Iran, Susan NoorMohammadi studied Architecture at the University of Tehran, and received her $\mathrm{PhD}$ in the College of Fine Arts, Faculty of Architecture in 2009. In 2007 she was a visiting scholar at the School of Architecture, the University of Sheffield, in England. Living in Germany she is a compassionate architect with a willingness to learn and to teach. In this paper, she proposes questions regarding the contribution of Bachelard's phenomenology of imagination in architectural-urban contexts. 